\title{
Parallel Electric Resistivity in the TFTR
}

\author{
Tokamak
}

\author{
M.C. Zarnstorff, K. McGuire, M.G. Bell, B. Grek. \\ D. Juhnson, D. McCune, H. Park, \\ A. Ramsey, and G. Taylor \\ Princeton Plasma Physics Laboratory \\ Princeton University \\ Princeton, N.J. 08543
}

\section{DISCLAIMER}

\begin{abstract}
This report was prepared as an account of work sponsored by an agency of the United States Government. Neither the United States Government nor any agency thereof, nor any of their employees, makes any warranty, express or implitd, or assumes any legal hability or tesponsibility for the accuracy, completeness, or usefulness of any information, apparatus, product, or process disclosed, or represents that its use would not infringe privalely owned rights. Reference herein to any specifie commercial product, process, os service by trade name, trademart. manufacturer, or otherwise does not necessarily constilute or imply ils endorsement, recommendation, or favoring by the United States Government or any agency thereof. The views and opinions of authors expressed herein do not necessariiy state or rellect those of the United Stales Government or any agency thereof.
\end{abstract}




\section{Introduction}

The electrical resistivity of a magnetized plasna parallel to the mag. netic field is a basic consequence of the electron parallel force-balance equation. ("lassical resistivity" is predicted for a near-Maxwellian unmagnetized plasma or for a plasma embedded in a uniform magnetic field (in particular $\Gamma B=0$ j. It is determined by the balance of the electric and friction forces. and includes the crnsequences of distortion of the electron distribution function away from a shifted Maxwellian. Neoclassical theor $y^{2.3}$ corrects the classical expression for the efferts of a poloidally nonuniform magnetic fieid strength in an axisymmetric toroidal plasma, in particular the parallel viscous damping due to magnetic trapping or magnetic pumping (fir collisionless or collisional electrons. respectively). Thus, experimental measurements of the resistivity are of fundamental importance in understanding parallel electron transport. In some theories, parallel electron transport is closely related to cruss-field transport; thus, an understanding of the parallel resistivity can give incight into the mechanisms of anomalous perpendicular transport. In addition, the resistivity is of practical importance in understanding and designing laboratory plasma arcs and pinches, such as tokamaks.

Previous measurements of the piasma resistivity in tokamaks, averaged over the plasma cross section. have been in agreement with the classical value 
in PLT. TEKT. ASDEX. ${ }^{\circ}$ and IT-60." have been between the classical and nesclassical values in .JET. and have been in agreement with neoclassical theory in a recent reanalysis of $\mathrm{JT}-60$ data. ${ }^{9}$ In addition. the resistivity was found to be anomalous when the current was being ramped up or down slowly un $\mathrm{JET}^{8,10}$ Local measurements of the resistivity were found to be in agreement with neoclassical theory for toroidal multipoles ${ }^{11}$ for the plateau and collisiona] regimes (but were anomalously large for the collisionless regime), and were between the classical and neoclassical predictions (but did not resolve between them) in the TEXTOR ${ }^{12}$ and $\mathrm{JET}^{8}$ tokarnaks (see Ref. 10 for differing conclusions). In sther experiments, the resistivity was assumed ${ }^{13}$ to be either classical or neoclassical as a way of inferring the plasma impurity content. Previous experiments with high $\beta_{P}$ auxiliary heated plasmas on $\mathrm{TFTR}^{14}$ and $\mathrm{JET}^{15}$ were found to agree with the predictions of the neoclassical boutstrap current in combination with neoclassical resistivity.

In this paper we compare the resistivity of TFTR ohmic plasmas with theoretical predictions nver a wide range of plasma parameters. Section II describes general experimental and plasma conditions, section III discusses the analysis method, section II presents the experiment al results, and section $\checkmark$ discusses and summarizes the work. 


\section{I1. Experimental Conditions}

The IFTK experiment has been described previnusly. ${ }^{\text {in }}$ The tukamak plasmas studjed here were heated ohmically and fueled by gas puffing at the plasma edge. The etolution of global parameters for a typical plasma are shown in Fig. 1.

The TFTR magnetic diagnostics are described in Ref. 17. The plasma current $I_{P}$ is measured by a poloidal Rogowski loop. The plasma positior., shape, and $.1 \equiv \beta_{p}-l_{3} / 2$ are obtained by fitting measured moments of the poloidal magnetic field distribution (by a poloidal arrat of loops) and the puloidal flux distribution (by six saddle-coils) outside the thin vacuum vessel (vessel field-penetration time $\sim 10 \mathrm{msec}$ ) using a filament cude. ${ }^{18}$ Here $3_{r} \equiv 2 \mu_{0} \tilde{p} / B_{P}^{2}(a)$ is the poloidal beta, $l_{i} \equiv \bar{B}_{P}^{2} / B_{F}^{2}(a)$ is the dimensionless internal inductance. $p$ is the plasma pressure. $B_{P}$ is the poloidal magnetic field strength, and the overbar indicates viume average. The toroidal roltage at the plasma surface is obtained by averaging the voltages measured on six toroidal loops (distributed polojidally) rorrected for the calculated time-derivative of the poloidal flux between each luop and the plasma. The poloidal voltage at the plasma surface is obtained using a poloidal loop part of the diamagnetic system) corrected for the calculatea time-derivative of the torcidal flux between the loop and the plasma. The time-evolution of the 
plasma current /r. plasma herizontal and radial position. and line-anerage

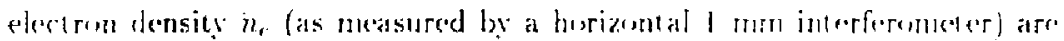
controlled by preprogrammed feedback linps. ${ }^{19}$

The electoun density $n_{\varepsilon}$ and temperature $T$, profiles are measured at a single time in each discharge by. Thomson scattering. ${ }^{20}$ see Fig. '2. The time erolution of the $n_{\mathrm{r}}$ profile is obtained by Abel inversion ${ }^{2 i}$ of the measurements of a ten-channel array of far-infrared interfermmeters. ${ }^{22}$ The time eunlution of the 7 , profile is measured by electron cyclotron emission (EC'E) radjemet ry ${ }^{23}$ calibrated by the Thumson scattering measurement. The time evolution of the $n_{\mathrm{e}}$ and $T_{\varepsilon}$ profiles for the plasma of Fig. 1 are shown in Fig. 3. The cent ral $Z_{\text {eff }}=\Sigma_{n_{1}} Z_{2}^{2} n_{\mathrm{e}}$. where the sum is over the jon species. is determined from tange-: :al and radial measurements of the visible bretusstrahlung emissian. ${ }^{2-1}$ as shown in Fig. 4. $Z_{a f f}$ is measured (using an array of visible bremsstrahlung detectors) to be spatially uniform in the heliam plasmas studied and in pre. vious deuterium plasmas. It is assumed to be unifortn for the deuterium plasmas studied here.

\section{Analysis}

Two slightly different me:hods have beren used in this study: full time. dependent analysis of an entire discharge using Thatsf 25 and mearequiliturium 
analysis at a single time using S.M.P. ${ }^{26}$ In both cases, the measured plasma kinctic parameters $\left(T_{e}, \pi_{e}\right)$ are mapped and symmetrized onto an magnetohydrodynamic equilibrium set of flux surfaces calculated self-consistently using the kinetic pressure profile and the magnetically measured shape and location of the outermost flux surface. The Thomson scattering measurements of the $T_{e}$ and $n_{e}$ profiles are each found to be symmetric within $=10 \%$ for $r<0.7 a$ in the plasmas studied.

TRANSP numerically evolves the poloidal field diffusion equation ${ }^{2}$

$$
\frac{\partial}{\partial t} \frac{\partial \psi}{\partial \rho}=\frac{\partial}{\partial \rho}\left[\frac{2 \pi\langle\boldsymbol{E} \cdot \boldsymbol{B}\rangle}{F\left\langle\boldsymbol{R}^{-2}\right\rangle}\right]
$$

on a toroidal flux surface grid, where $v$ is the poloidal flux contained within a given flux surface, $R$ is the local major radius, $F=R B_{T}, B_{T}$ and $B$ are the toroidal and total magnetic field, $\boldsymbol{E}$ is the electric field, $p$ is a radial flux surface coordinate, the standard flux surface average is $(A) \equiv$ $\partial \rho / \partial I^{\circ} f A d S /|\nabla \rho|, l^{*}$ is the volume enclosed in the flux surface, and $d S$ is an area element on the flux surface. The measured total plasma current provides the external boundary condition for the solution. and the flux surface averages are evaluated using a moments-solution ${ }^{27}$ to the Grad-Shafranov equation using the measured plasma shape and kinetic pressure profile, and the calculated current profile. The parallel electric field on each flux surface is related to the parallel current density $J$ by the flux-surface-averaged 
electcon parallel force-balance equation, or Ohm's law.3

$$
\left(\boldsymbol{E} \cdot \boldsymbol{B}_{i}=\eta_{1}\left(\left(\boldsymbol{J}-\boldsymbol{J}_{\mathrm{DK}}\right) \cdot \boldsymbol{B} ;,\right.\right.
$$

where $J_{D R}$ is any current not driven by the electric field and $\eta_{\|}$is the parallel resistivity. The plasma resistivity on each flux surface is calculated from the measured plasma parameters using a theoretically predicted resistivity. The predicted resistivity for a flow-shifted Maxwellian electron distribution function is

$$
\eta_{i: m x}=\frac{m_{e} Z_{e f f} \nu_{e e}}{n_{e} e^{2}}
$$

where $m_{e}$ is the electron mass, $e$ is the electron charge, and $\nu_{e x}$ is the electronelectron collision frequency. ${ }^{28}$ Classical resistivity is accurately given by ${ }^{29}$

$$
\eta_{i \mid c l}=\eta_{i \mathrm{mn} \times}\left[\frac{1-1.198 Z_{\text {eff }}-0.222 Z_{e f f}^{2}}{1-2.966 Z_{\text {eff }}+0.753 Z_{\text {eff }}^{2}}\right],
$$

and neoclassical resistivity by ${ }^{30}$

$$
\eta_{\mid \mathrm{nc}}=\eta_{i|c|}\left(1-\frac{f_{t}}{1-\xi \nu_{\text {ee }}}\right)^{-1}\left(1-\frac{c_{R} f_{t}}{1-\xi \nu_{\text {ee }}}\right)^{-1},
$$

where $f_{t}$ is the trapped particle fraction, $c_{R}=0.56 Z_{\text {eff }}^{-1}\left(3.0-Z_{\text {eff }}\right) /(3.0+$ $\left.Z_{\text {eff }}\right), \xi=0.58+0.20 Z_{e f f}, \nu_{e} \equiv \nu_{e} /\left(\epsilon^{3 / 2} \omega_{b}\right) . \nu_{e}$ is the electron collision frequency, $\epsilon \equiv r / R, r$ is the local minor radius. and $w_{b}$ is the electron bounce frequency. The neoclassical resistivity is larger than the classical value due to damping of poloidal electron motion by neoclassical parallel viscosity. Relativistic corrections to the resistivity $y^{31}$ are negligible, for the plasmas studied, 
as $T_{e} \ll 511 \mathrm{kel}$. The only non-Ohmic current $\boldsymbol{J}_{\mathrm{DR}}$ predicted for the plasmas studied here is the neuclassical bootstrap current, which arises from the interaction of the Pfirsch-Schluter current with the neoclassical parallel viscosity. This is calculated using expressions ${ }^{3,29}$ including the effects of impurities and finite aspect ratio, and is predicted to be small (but systematically significant) due to the low $\beta_{\boldsymbol{P}}$ achieved Ohmically (see Table 1). An uptional Kadomtsev sawtooth reconnection model ${ }^{32}$ can be applied in TRA.VSP to redistribute the current profile each time a sawtonth is observed experimentally. In other experiments ${ }^{33.34}$ the observed change in the current profile due to sawteeth is less than predicted by the Kadomtsev model; thus, the effects of sawteeth on the current profile evolution should be bounded between no sawtooth-redistribution and the Kadomtsev model.

The results of these calculations are various predictions (for a given the. oretical resistivity and sawtooth model) that can be compared with experimental measurements, such as the $q$ prufile and the parallel voltage per toroidal transit at the surface of the piasma

$$
\begin{aligned}
i_{\text {iut }} & \left.\equiv \frac{2 \pi\langle\boldsymbol{E} \cdot \boldsymbol{B}\rangle}{F\left(R^{-2}\right)}\right|_{a} \\
& =\frac{\partial \psi(a)}{\partial t}-\frac{1}{q(a)} \frac{\partial \phi(a)}{\partial t} .
\end{aligned}
$$

where $\phi$ is the toroidal flux contained within the fux surface and $q \equiv \partial \phi / \partial \psi r$ is the safety factor. 
The SNAP analysis is similar to the TRANSP analy'sis. except that it solves for the steady-state current profile and assumes circular cross-section fiux sur. faces. In many TFTR plasmas, the current profile does not reach steady state during the finite pulse length available ( $<8$ ser). In order to analyze these plasmas with SNAP the effective surface woltage $l_{\text {sur }}=I_{\text {sur }}-\frac{1}{4} \mu_{0} R I_{p} \partial l_{v} / \partial t$ is used. approximatel.' correcting for the extra voltage due to the equilibrat. ing inductance. This expression for 1 sur above has taken advantage of the restriction of the SNAP analysis $t o$ times when $\partial I_{P} / \partial t=\partial R(a) / \partial t=0$. For all of the SNAP results discussed here the inductance is nearly equilibrated. with less than a $10 \%$ difference between $l_{\text {sur }}$ and $!$ sur.

\section{Experimental Results}

The resistivity has been analyzed for a wide variety of ohmic plasmas from the 1986, 1987, and 1988 TFTR runs. whose parameters are summarized in Table 1 and Fig. 5. These plasmias were selected by having an adequate set of diagnostic measurements, by not showing significant distortion of their ECE spectrum (which would indicate the presence of high-energy nonthermal electrons), and by not being detached ${ }^{35}$ or having a MARFE, ${ }^{36}$ Figure 6 compares the measured evolution of lisur for the plasma of Fig. 1 with the TRANSP predictions using classical and neoclassical resistivity. The 
predictions of the two theories are well separated throughont the discharge. and the nencinssical prediction is in gurd agreement with the measurement throughoui (including the slow Is ramp-up and -down phases). Due to the low $\beta_{P}$ achieved ohmically, the ralculated total bootstrap curent is small $(\sim 100 \mathrm{k}: \mathrm{i})$, decreasing the neoclassical $V_{\text {sur }}$ by $5.5 \%$ during the $I_{P}$-constant period. The pussible effect of Kaciontsev sawtooth reconnection is very small. and is calculated $t o$ increase the neoclassical $l_{\text {sur }}$ by less than $1 \%$ relative to the curve in Fig. 6. The results of similar analysis using TR.ASP and S.i.A are summarized in Fig. ifor the plasmas of Fig. 5. The uncertainlies shown in the figures represent the standard deviation of the distribution of results obtained by varying all of the experimental measurements within their range of uncertainty (both systematic and statistica!). as estimated by a Monte-Carlo ensemble. On the average, $49 \%$ of the calculated uncertainty in $V_{\text {sur }}$ is due to uncertainty in $T_{e}, 33 \%$ is from uncertainty in the visible bremsstrahlung is anal, and $18 \%$ is from uncertainty in the $n_{e}$ profile shape. In general, the measurements indicate that the average resistivity is equal to the neoclassical prediction within the experimental rricertainty. It should be noted that, while the average experimental resistivity is roughly twice the classical prediction, there is not a constant ratio between them. As shown in Fig. 8, this ratio varies (modestly) with electron collisionality $\nu_{-e}$ as ex- 
nected from nocolassical thersy. In particular. see Fig. 8(c), the ohserved resistivity is in dis gretment with the mue expected for purely liaxwollian electrons. Taken as an ensemble. the data of Fig. 8 inmicate that the ratio of the neuclassically predicted $V_{\text {, ur }}$ io the measured $l_{\text {sur }}$ is $1.01 t=0.0 \mathrm{tr}$.

While a direct me isurement of the plasma current or $q$ profile was not available for these experiments, experimental information about the current profile shape can be obtained from the location of the $q=1$ suriace. The $q$ - I surface can be unambiguously located by observation of the ivitial position of the min .. ?:\} sawtush precursor, as measured by a high speed soft $x-r a y$ camera. $^{3 \hat{*}}$ in addition. the sawtuoth inversion sadius typically agrees well with the $m / n=1 / 1$ prosition, and gives a more generally available in. dication of the $q=1$ minor radius. Figure 9 compares the calculated radius of the $q=$ J surface (with and without the Kadomtsev sawtooth modei) with t? observed sawtooth inversion radius (also measured by the soft $x$-ray camera) and the observed $m / n=1 / 1$ location for the piasma of Fig. 1. The nenclassical-resistivity calculation accuately predicts the evolution of the $q=1$ radius. including the coincidence of the initial appearance of a $q=1$ surface and the first observed sawtouth. Isi contrast. the classical-resistivity prediction shows no $q=1$ surface during the entire discharge, in clear conflict with the observed sawceeth and the measured $q=1$ location. With classical 
resistivity, the minimum value of $q$ predicted for this discharge is 1.2 , occurring at the end of the analysis $(\sim \overline{s e c})$ when Is has dropped to 0.7 MA. For all the plasmas studied. the predicted and measured radius of the $q=1$ surface nere found to agree with neoclassical resistivity, and no $q=1$ surface was predicled with classical resistivity. The time evolution of $\lambda$ also gives an integral measure of the current profile shape. While the mcasured evolution and value of $A$ is ger:erally in better agreement with the neoclassical prediction than the classical prediction, the difference between the two predictions is usually not large enough to be experimentally significant.

\section{Discussion}

The above nbservations indicate that the parallel plasma resistivity is in good agreement with the predictions of neoclassical parallel-transport theory wer a wide range of plasma parameters from the banana regime into the plateau regime. This agreement is found when the plasma current is static or is being ramped up or down at a moderate rate $\left(\partial I_{P} / \partial t \leq 1 \mathrm{MA} / \mathrm{sec}\right)$. No attempt has been made to analyze the very rajid injtial current ramp $\left(\partial I_{P} / \partial t \geq 5 \mathrm{MA} / \mathrm{sec}\right.$ during the first $\left.0.2 \mathrm{sec}\right)$ on TFTR.

While the observations indicate that the parallel electron transport is as expected from nenclassical theory, the observed perpendicular transport 
is typically much larger ( by a factor $=100$ ) than neuclassical predictions. This combination is expected. for example. if the perpendicalar transport is dominantly caused by elect costatic turbulence ${ }^{38}$ It is easil! seen that if the perpendicular diffusion coefficient for electron parallel momentum is comparable to the observed perpendicular electron thermal diffusion crefficient $\left(x_{*}-1 \mathrm{~m}^{2} / \mathrm{sec}\right)$, the effect on the apparent resistivity is negligible. Alternalively: it has been propused ${ }^{29-31}$ that an adequate self-consistent explànation of the anomalcus perpendicular transport could be rbtained via an anomalousiy large $\nu_{e e}$ possibly due to the inceraction between the electrons and turbulent structures. Such an increase in $\nu_{e t}$ increases the parallel viscosity lin the collosinnless regime), and thus increases the resis:jvity bootstrap current. and Hare pinch nver the neoclassica? values. The increased resistivity and boststrap current largely cancel. resulting in the overall appearance of classical resistivity. ${ }^{40}$ for an ohmic plasma that remains in the collisionless regime. The general case is more complicated, ${ }^{42}$ but consistently leads u, the appearance of anomalous (non-neoclassical) resistivity. This is in conflict with the above observatjons, indicating that it is very unlikely that an anomalous $\nu_{e t}$ is the cause of anomalous perpendicular transport.

Finally, the persistent and long-standing observations of classical resistiviț in small tokamaks ${ }^{4-6}$ stand in sharp contrast $t$, the observations presented 
nere. Due to the fundamental connection between the parallel resistivity and faralley and sume perpendicularj transport processes. this may imply that the electron transport mechanisms are iundamentally different in large and small tokamak experiments.

In conclusion, the ohmic resistivity and general current profile shape in TF'TR is seen to be in good agreement with neoclassical predictions for the available range of plasma parameters for both near-equilibrium and dynamic (current changing) situations. The observed resistivity is in disagreement with predictions neglecting torcidal (trapped particle) effects or inwolving significantly anomalous resistivity in conjunction with anomalous transport.

\section{Acknowledgments}

We are grateful for the support of the TFTR group and for discisssions with J.D. Callen. R.J. Goldston. R.J. Hawryluk. D.Ml. Meade. S. Scuit. and P. Terry.

This work was supported by US Department of Energy contract DEAC02-r6-CHO-3073. 


\section{References}

L. Spitzer. Jr, and K. Härm. Phỵs. Kev. 89. 977 (1953).

${ }^{2}$ F. L. Hinton and R. D. Hazeltine. Rev. Hod. Phys. 42, 239 (1976).

${ }^{3}$ S. P. Hirshman and D. J. Sigmar, Nucl. Fision 21. 1079 (1981).

${ }^{4}$ E. Neservey: M. Bitter. C. Daughney. D. Eames. P. Efthimion. E. Hinnur, R. Hulse. D. Prst. K. Satu. S. Suckewer, and S. von Goeler. Nucl. Fusion 24. $3(1984)$.

${ }^{5}$ J. L. Porler. P. E. Phillips. 5. C. McCool, S. B. Kim, D. W. Koss, W. H. Miner. and J. ('. Miley. Vucl. Fusion 27. 203 (1987).

${ }^{6}$ H. Köhr. K. H. Steuer, and the ASDEX Team, Ker. Scj. Instrum. 59. 1875 (1988).

‘T. Hirąama. K. Shimizu. H. Shirai. M. Kikuchi. N. Hosogane. H. Yushida. and JT-60 Team. in Proceedings of the 15th European Conference on Contralled Fuszon and Plasma Heating. EPS. (ieneva, 1988, volume 3. p. 1065.

${ }^{8}$ D. V. Bartlett. K. J. Bickerton. 11. Brusati. [0. J. Camphell. J. P. Christiansen. J. G. Cordey. S. Corti, A. E. Custley A. Edwards. J. Fessey: M. Gadeberg. A. Gibson. R. D. Gill, X. Guttardi. A. Gondhalekar. C. IV. 
(iuwers, F. Hendriks, O. \. Jarvis. E. Källne, .J. Källne. S. Kissel. L. ('. J. M. [. Kuck, H. Krause. E. Lazzaro, P. J. Lumas, F. K. Mast, P. I. Morgan. P. Mielsen. R. Prentice. R. T. Ross. J. O'Ruurke. G. Sadler. F. ('. Schüller. M. F. Stamp. P. E. Strut L. D. R. Summers. A. Tanga. A. Taroni. P. R. Thomas, F. Tibone, G. Tonetti. B. J. D. Tutbing, and M. L. Watkins. Yucl. Fusion 28, i3 (1988).

${ }^{9}$ II. Kikuchi. M. Azumi, S. Tsuji, K. Tani, and H. Kubo. Vucl. Fusion 30, $3+3$ (1990).

${ }^{10}$ D. J. Campbell, E. Lazza:o, M. F. F. Nave, J. P. Christiansen, J. G. Cordey. F. C'. Schüller. and P. R. Thomas, Yucl. Fusion 28, 981 (1988),

"J. F. Etzweiler and D. A. Brouchous. Phys. Fluids 23. 254i (1980).

${ }^{12} \mathrm{H}$. Soltwisch, E. Graffmann. ․ Schlüter. and G. Waidmann, in Proctedings of the International Conference on Plasmia Phystcs, Invtled Papers (Lausanne), edjted by M. Q. Tran and R. J. Verbeek, CEC, Brussels. '1984. volume 1, p. 499.

${ }^{13}$ R. M. Wieland, H. C. Howe, E. A. Lazarus. M. Murakami, and ('. E. Thomas. Nucl. Fusion 23, 447 (1983).

H.M. C. Zarnstorf, M. G. Bell, M. Bitter, R. J. Goldston. B. Grek. K. J. 
Hawrỵluk, K. Hill. D. Juhnson. D. NcC'une. H. Park. A. Ramsey. G. TayLor. and K. Wieland. Phes. Rev. Lett. 60, 1306 (1988).

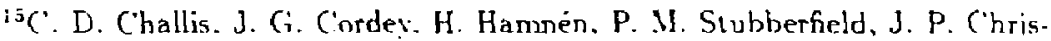
tiansen. E. Lazzaro, D. G. Muir, D. Stork, and E. Thompson, Nucl. Fusiun 29. 563 (1989).

${ }^{6}$ R. J. Hawryluk. V. Arunasalam, W. G. Bell, M1. Bitter, W. K. Blanchard. ․ L. Bretz, R. Budny; C. E. Bush. J. U. Callen, S. A. Colen. S. K. C'ombs. S. L. Daris. D. L. Dimock, H. F. Dylla, P. C. Efthimion, L. C. Emerson. A. (. England. H. P. Eubank. R. J. Fonck. E. Fredrickson, H. P. Furth. G. Gamme!. R. J. Goldston. B. Grek. L. R. Grisham. G. Hammett. W. W. Heidbrink. H. W, Hended, K. W. Hill, E. Hinnus. S. Hiro.. H. Hsuan. R. A. Hulse. K. P. Jaehnig, D. Jassby, F. (. Jobes. D. V: Johnson, L. C. Johnson, R. Kaita, R. Kamperschroer, S. II. Kave. 5. J. Kilpatrick. F. J. Knize, H. Kugel. P. H. LaMarche. B. LeBlanc, R. Little, C. H. Ma. D. M. Manıs. D. K. Mansfield, R. T. McCann. M. P. McCarthy, D. C. McCune. K. WcCiujre, D. H. Mc Veill. D. M. Meade. S. S. Medley, D. R. Mikkelsen, S. L. Milora, W. Morris, D. Mueller. V. Mukhovator, E. B. Nieschnidt, J. O'Kourke, D. K. Owens. H. Park. D. Pomphrey B. Prichard, A. T. Ramsey. M. H. Redi. A. L. Ruquemure. P. H. Rutherford, N. R. Sauthoff, G. Schilling. J. Schivell. G. L. Schmidt. 
S. D. Scott. S. Sesnic. J. C. Sinnis. F. J. Stauffer. B. (.. Stratton. C. D. Tait. G. Taỵlor. J. K. Timberlake. H. H. Fowner. M. Vlrickson. V. Vershkor, S. wn Goeler. F. Wagner. R. Wieland. J. B. Wilgen, M. Williams. K. L. Wong. S. Jushikawa, R. Yoshino. K. H. Young. M. C: Zarnstorff. 1. 5. Zaveryaer, and S. J. Zweben, in Plasma Physacs and Controllad Vuclear Fuszon Research, IAEA, Vienna, 1987, volume 1. p. 51.

'J. Coonrod. M. G. Bell. R. J. Hawryluk, D. Mueller, and G. D. Tait. Rev. Sci. Instrum. 56, 941 (1985).

${ }^{18}$ D. W. Swain and G. H. Neilson, Nucl. Fusion 22. 1015 (1982).

${ }^{19}$ R. D. Woulley, M. G. Bell, J. Coonrod, P. Efthimion. R. J. Hawryhuk. W. Hojsak. R. J. Marsala, D. Mueller, W. Rauch. G. D. Tait. C. Taỵlor. and M. Thompson, Fusion Tech. 8. $180 \mathrm{~T}$ (1985).

${ }^{20}$ D. Johnson, N. Bretz, D. Dimock, B. Grek, D. Long. K. Palladino. and .E. Tolnas. Rev. Sci. Instrum. 57, 1856 (1986).

${ }^{21}$ H. Park, Plasma Phys. Controlled Fusion 31, 2035 (1989).

${ }^{22}$ D. K. Mansfield. H. K. Park, L. C. Johnson, H. M. Anderson, K. C'houinard. V. S. Foote, C. H. Ma, and B. J. Clifton. Appl. Opt. 26. 1169 (1987).

${ }^{23} \mathrm{G}$. Tay/or. F. Efthimion, M. McCarthy, V. Arunasalam. K. Bitzer. J. Brter. 
R. Cutler. E. Fredd. H. A. Goldman. and I). Kaufman, Rev. Sci. Instrum. 55, $1739(1984)$.

${ }^{24}$ A. T. Ramsey and S. L. Turner, Rer. Sci. Instrum. 58, 12]1 (1987).

${ }^{25}$ R. J. Hawryluk, in Phystcs of Plasmas Close to Thermonuclear Conditions. edited by B. Coppi et al., CEC, Brussels, 1980, volume 1. p. 19.

${ }^{26}$ H. Towner and R. J. Goldston. Bull. Am. Phys. Soc. 29, 1305 (198t).

${ }^{2 \pi}$ L. L. Lan, R. M. Wijeland, MA. A. Houlberg. and S. P. Hirshman. Computer Phỵs. Comm. 27, 129 ([982).

${ }^{28} \mathrm{~S}$. 1. Braginskji. in Revicus of Plasme Physics, Consultants Bureau, New York, 1965, rolume 1, p. 205.

${ }^{29}$ S. P. Hirshman. Phys. Fluids 21, 1295 (1978).

${ }^{30}$ S. P. Hirshman, R. J. Hawryluk, and B. Birge, Nucl. Fusion 17, 611 (1977).

${ }^{31}$ B. J. Braams and C. F. F. Karney, Phỵs. Fluids B 1, 1355 (1989).

${ }^{32}$ B. B. Kadomtsev, Sov. J. Plasma Phỵs. 1, 389 (1975).

${ }^{33}$ T. H. Osborne, R. N. Dexter. and S. C. Prager, Phys. Rev. Lett. 49. $73 \dashv$ (1982)

${ }^{34}$ H. Soltwisch, Rev. Sci. Instrum. 59, 1599 (1988). 
${ }^{35}$ J. D. Strachan, F. P. Buody, C. E. Bush, S. A. C'when. B. Grek. L. Girisham. F. C. Jubes. D. W. Mhnson. D. K. Mansfield. S. S. Medley. W. Morris. H. K. Park. J. F. Schivell, G. Tayior, K. L. Wong, S, Yoshikawa. M. ( . Zarnstorff, and S. J. Zweben, J. Nucl. Mater. 145-147. 186 (1987).

${ }^{36}$ B. Lipschulzz. B. LaBumbard, E. S. Marmat, M. M. Pickrell. J. L. Terry. K. Watterson. and S. M. Wolfe, Nucl. Fusion 24, 97T (1981).

${ }^{3 \top}$ K. McGuire, R. J. Coichin, E. Fredrickson. K. Hill, L. C. Johnson, W. Morris. Y. Pare, N. Sauthof, and S. von Goeler, Rev. Sci. Instrum. 57. 2136 (1996).

${ }^{38}$ K. C. Shaing, Phys. Fluids 31, 2249 (1988).

${ }^{39}$ G. V. Pereverzev and P. N. Yushmanov, Sos. J. Plasma Phys. 6. 543 (1980).

${ }^{40} \mathrm{~J}$. W. Connor ard J. B. Taylor, Comments Plasma Phys. Controlled Fusion $11,37(1987)$.

${ }^{43}$ L. Kovrizhnykh, Sov. J. Plasma Phys. 14. 834 (1988). 


\section{Tables}

TABLE 1 . The range of discharge parameters for the plasmas studied.

\begin{tabular}{ll}
\hline Ion Species & $\mathrm{D}, \mathrm{He}, \mathrm{G}$ \\
$I_{F}$ & $0.7-2.2 \mathrm{Ml}$ \\
$B_{T}$ & $3.9-5.1 \mathrm{~T}$ \\
$R$ & $2.3-2.5 \mathrm{~m}$ \\
$R / a$ & $3.0-3.6$ \\
$\bar{n}_{e}$ & $0.5-9.0 \times 10^{19} \mathrm{~m}^{-3}$ \\
$T_{\mathrm{r}}(0)$ & $1.8-5.4 \mathrm{keV}$ \\
$Z_{e f f}$ & $1.4-6.4$ \\
$\beta_{P}$ & $0.06-0.36$ \\
\hline
\end{tabular}




\section{Figures}

FIG. 1. Time evolution of $I_{P}, R, A, I_{s u r}$ and $\bar{n}_{w}$ the line average electron density for a trpical helium TFTh Ohmic plasma.

FIC. 2. Kadial profiles of (a) $T_{e}$ and (b) $n_{e}$, measured in the horizontal midplane by Thomson scattering for the plasma of Fig. 1 at $t=3.9 \mathrm{sec}$. The error bars represent the standard deviation in the value from the fit to the scattered spectrum. The systematic uncertainty of $T_{e}$ is calculated to have a standard deviation of $5 \%$ of the measured values.

FIG. 3. Contour plots of the time evolution of the (a) $T_{e}$ and $(b) n_{e}$ profiles for the plasma of Fig. 1, as measured by EC'E spectruscupy (calibrated to Thomson scattering) and the interferometer array, respectively: (ronLour intervals (and lowest contour values) are $200 \mathrm{eV}$ and $5 \times 10^{19} \mathrm{~m}^{-3}$. respectively.

FIG. 4. The time evolution of $Z_{\text {eff }}$ for the plasma of Fig. 1. calculated from a visible bremsstrahlung measurement along a tangentially viewing churd.

FJG. 5. Range of plasma parameters studied. where $g(a)$ is the edge safetyfactor and $\nu_{. e}(a / 2)$ is the electron collisionality parameter at $r=a$ '. Solid circles ( $\bullet$ ) indicate helium plasmas (at the end of the constant current period) analyzed using TRA.NSP, open circles $(0)$ indicate helium 
plasmas analyzed using S.iAP, and $(x)$ indicate deuterium plasme; ana. lyzed using SNAP.

FIG. 6. Time evolution of $r_{\text {sur }}$ for the plasma of Fig. 1 : (a) measured. (b) predicted using neoclassical resistivity, and (c) predicted using classical resistivity:

FIG. 7. Predicted values of $\mathrm{V}_{\text {gur }}$ (for (a) neoclassical and (b) classical resistivity) vs. measured values. Solid circles $(\bullet)$ indicate helium plasmas (at the end of the constant current period) analyzed using TK.A.TSP, open circles $(0)$ indicate helium plasmas analyzed using SNAP, and $(x)$ indicate deuterium plasmas analyzed using SNAP.

FIG. 8. Ratio of predicted to measured values of $l_{\text {sur }}$ vs. $\nu_{\text {ee }}$ at $r=a_{/} 2$. for (a) neoclassical, (b) classical resistivity, and (c) the flow-shifted Maxwellian resistivity. Solid circles ( $\bullet$ ) indirate helium plasmas (at the end of the constant current perjod) analyzed using TRANSP, open jircles $(0)$ indicate helium piosmas analyzed using SNAP, and $(x)$ indicate deuterium plasmas analyzed using SNAP.

FIG. 9. Time evolution of the radius of the $q=1$ surface: (a) $m: n=1$ precursor radius, (b) sawtooth inversion radius: (c) predicted using nerclassical resistivity without redistribution of the current profile by saw- 
teeth, and (d) predicted using neoclassical resistivity and the Kadomtser sawtorth model. The prediction using classical resistivity does not have a $q=1$ surface in the plasma at any time. 

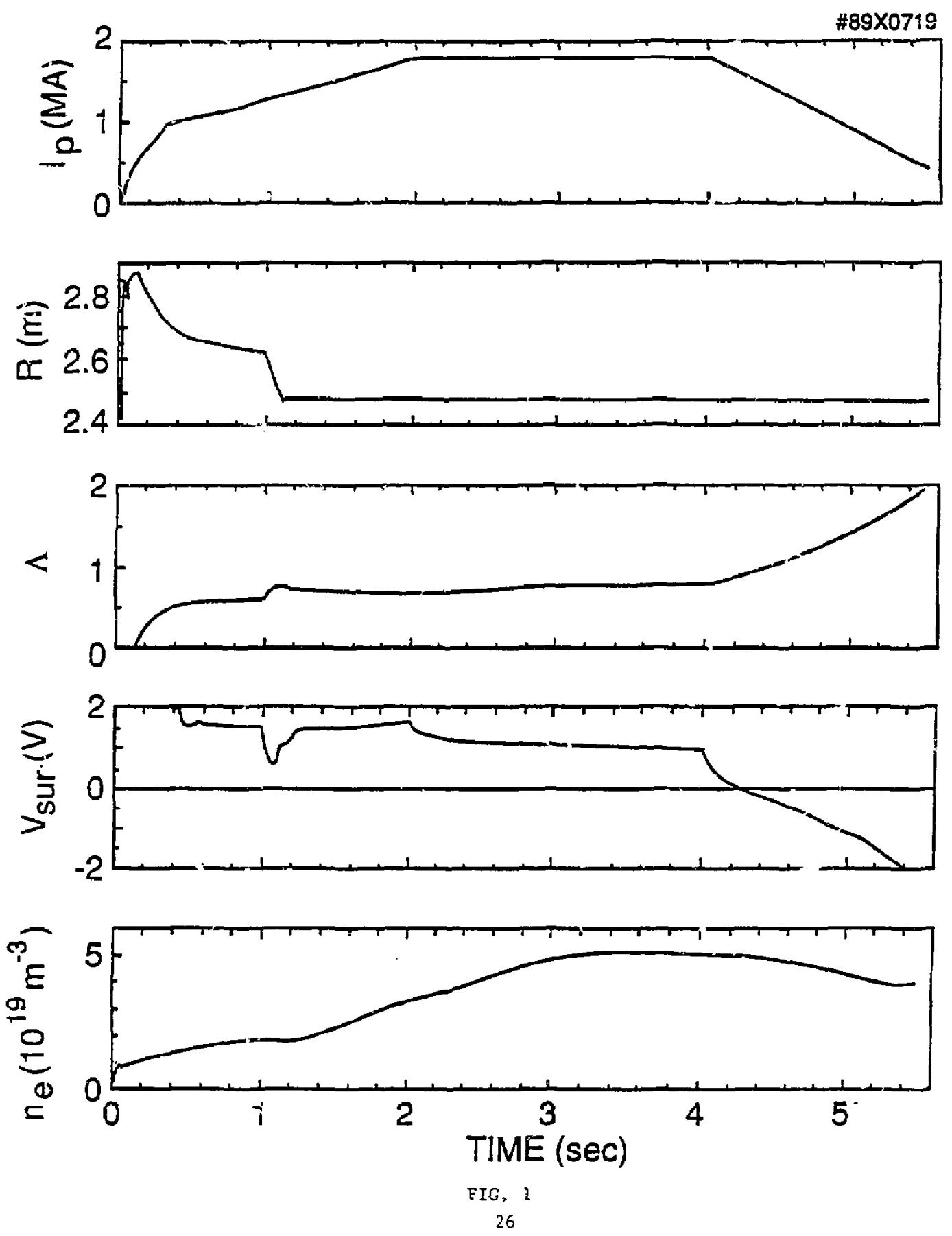

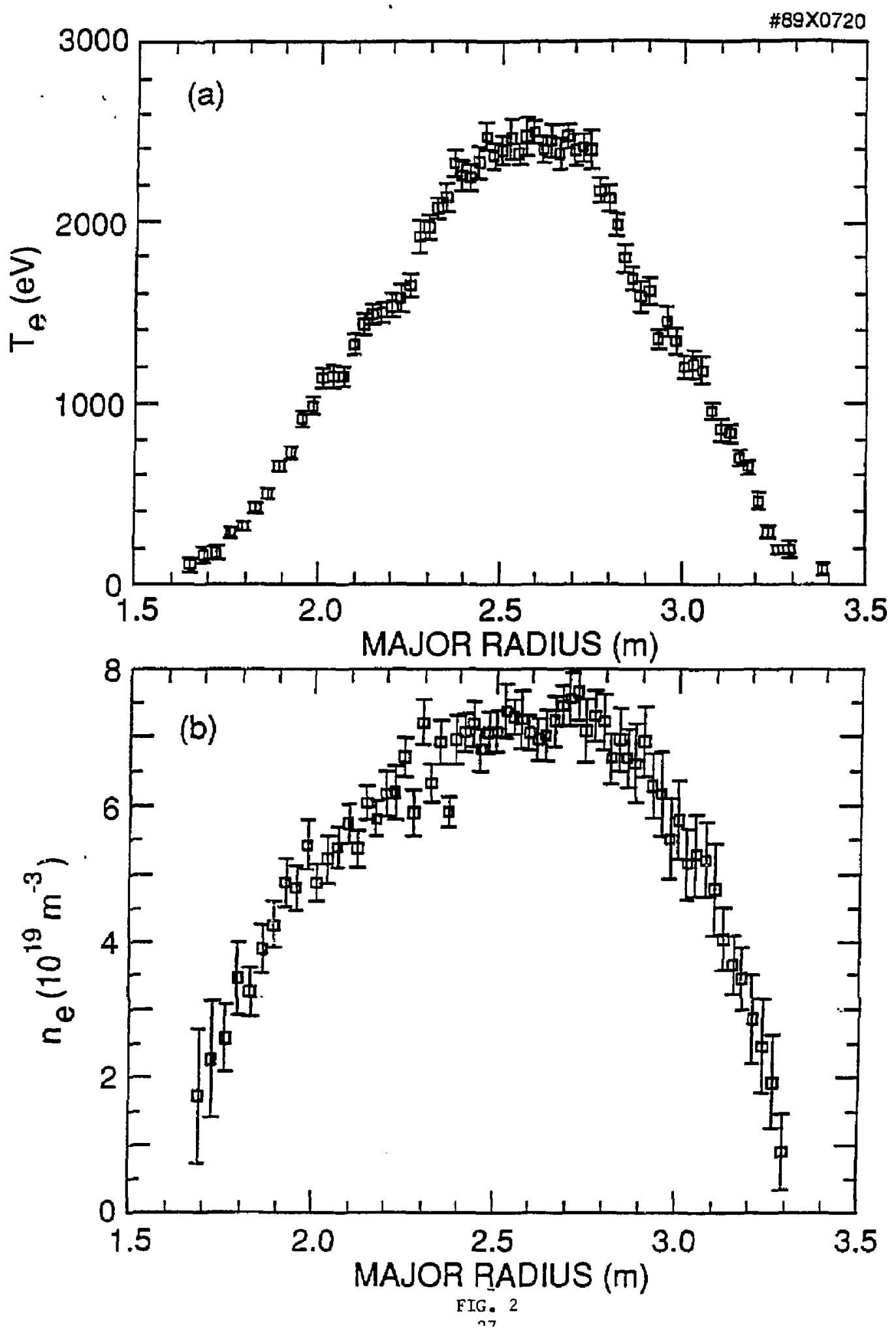

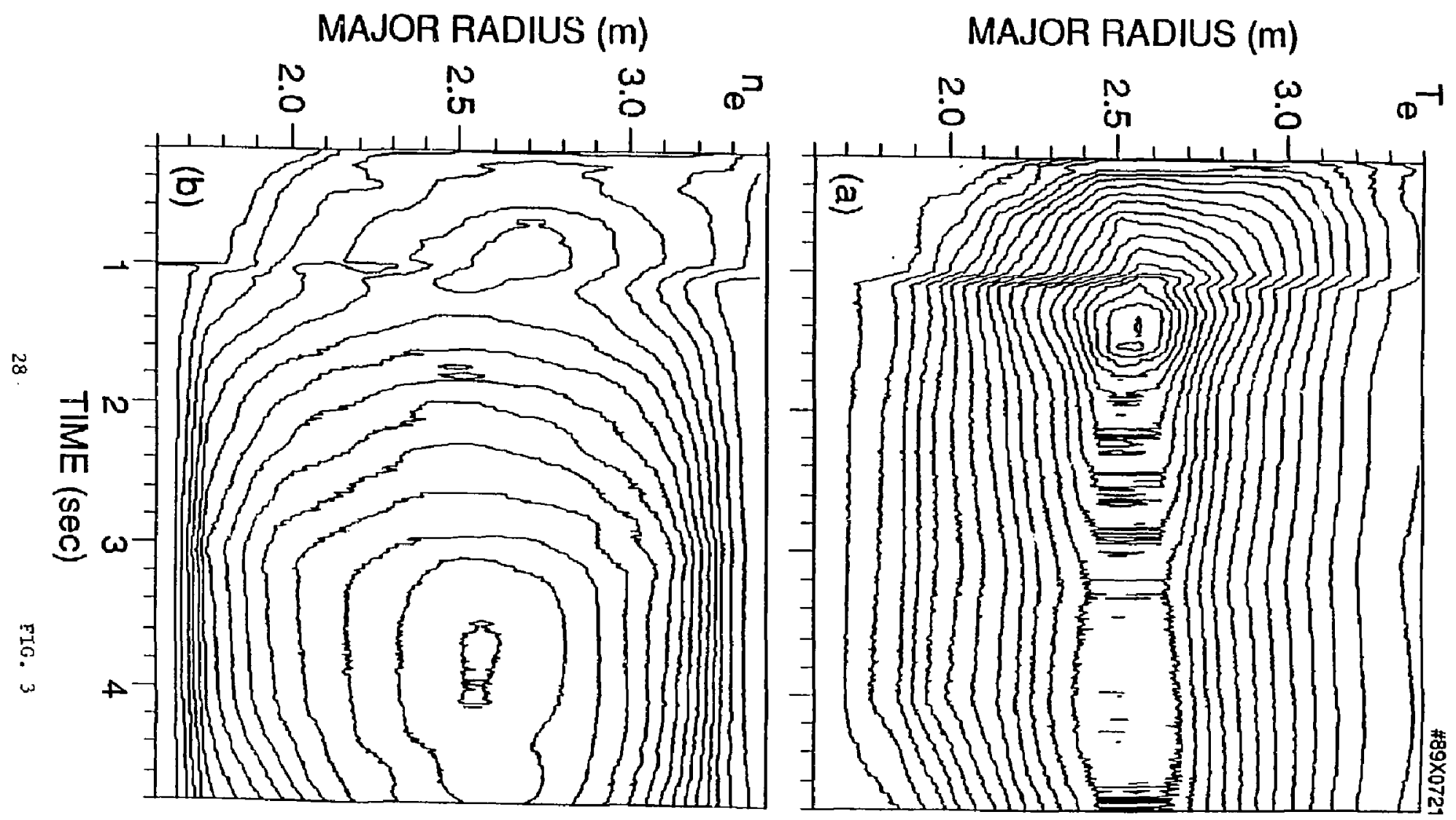


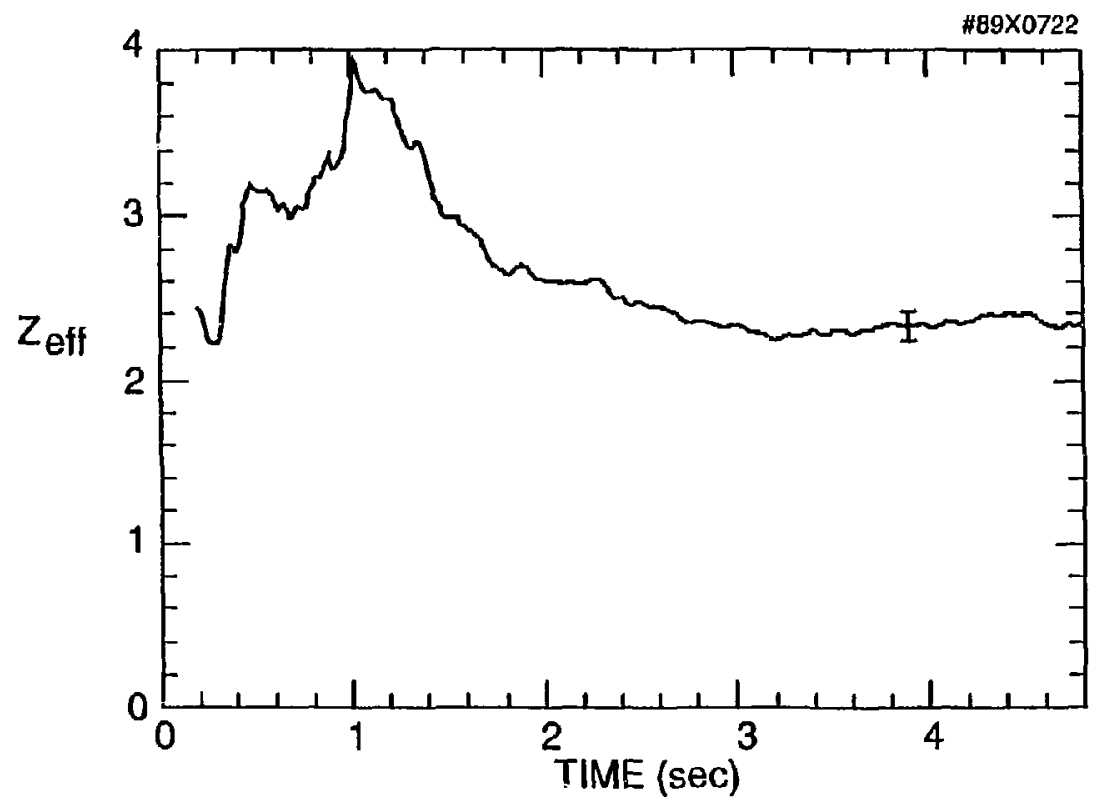

FIG. 4 


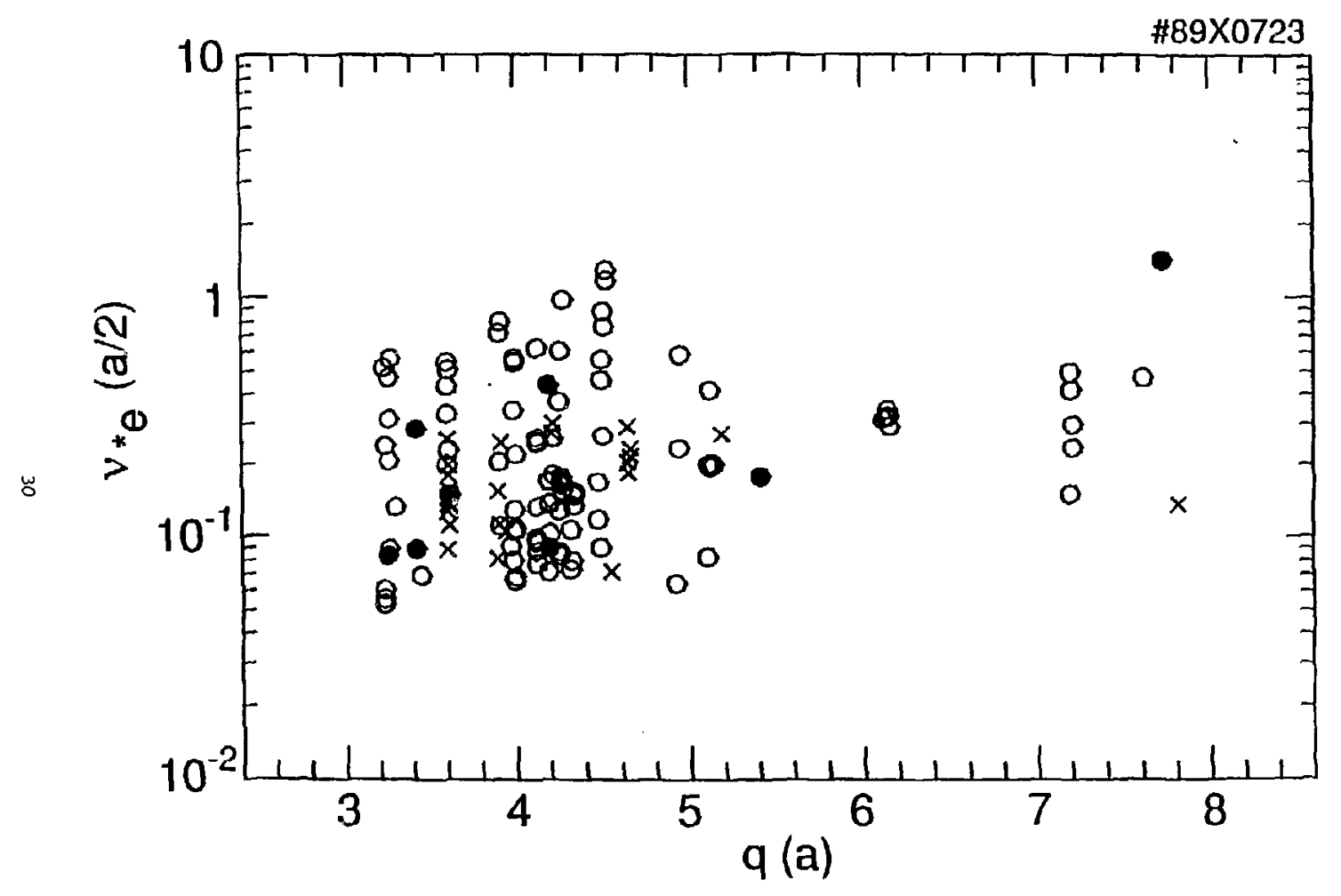

FIG. 5 


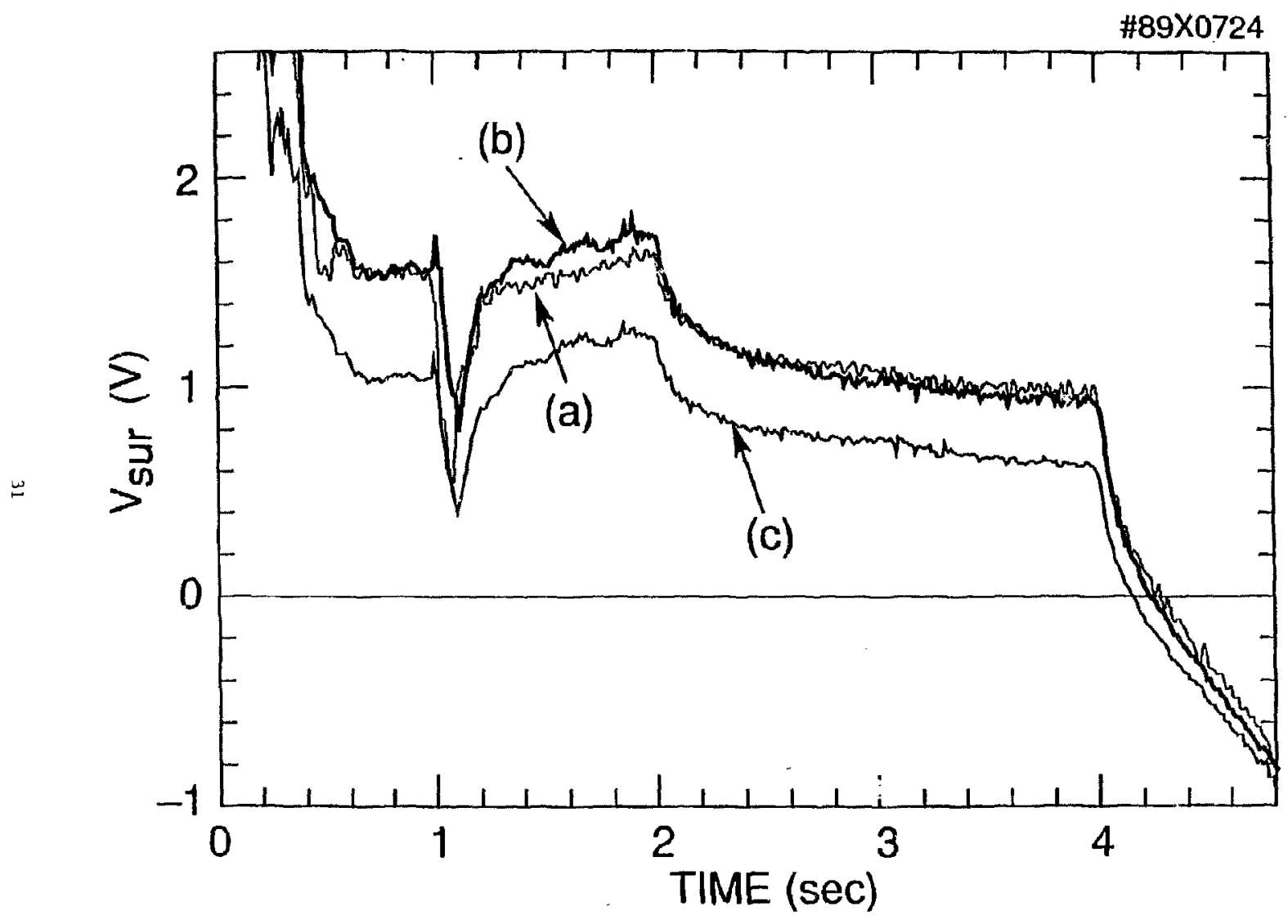

FIs. 6 
\#89X0725

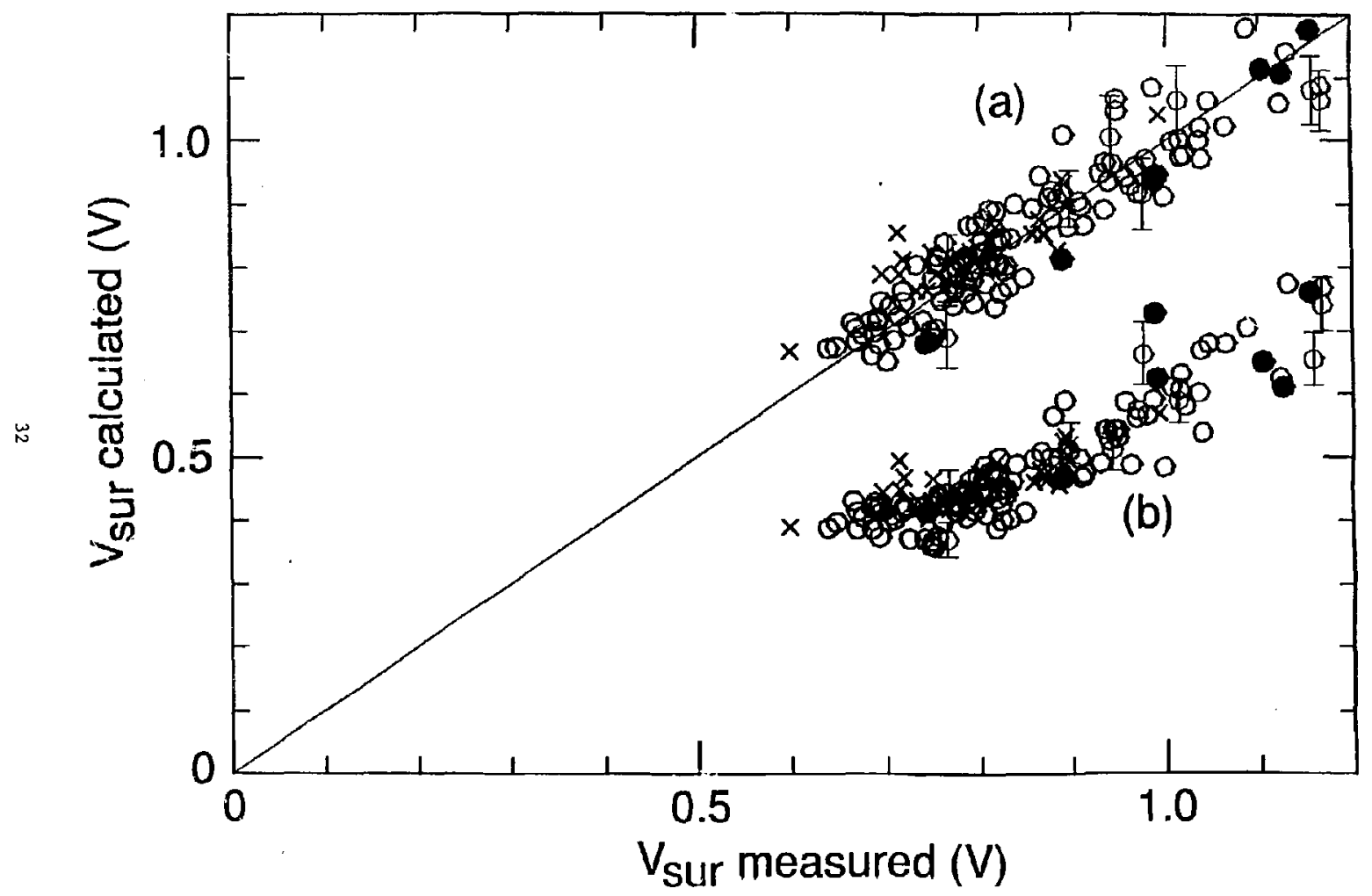

vic. 7 

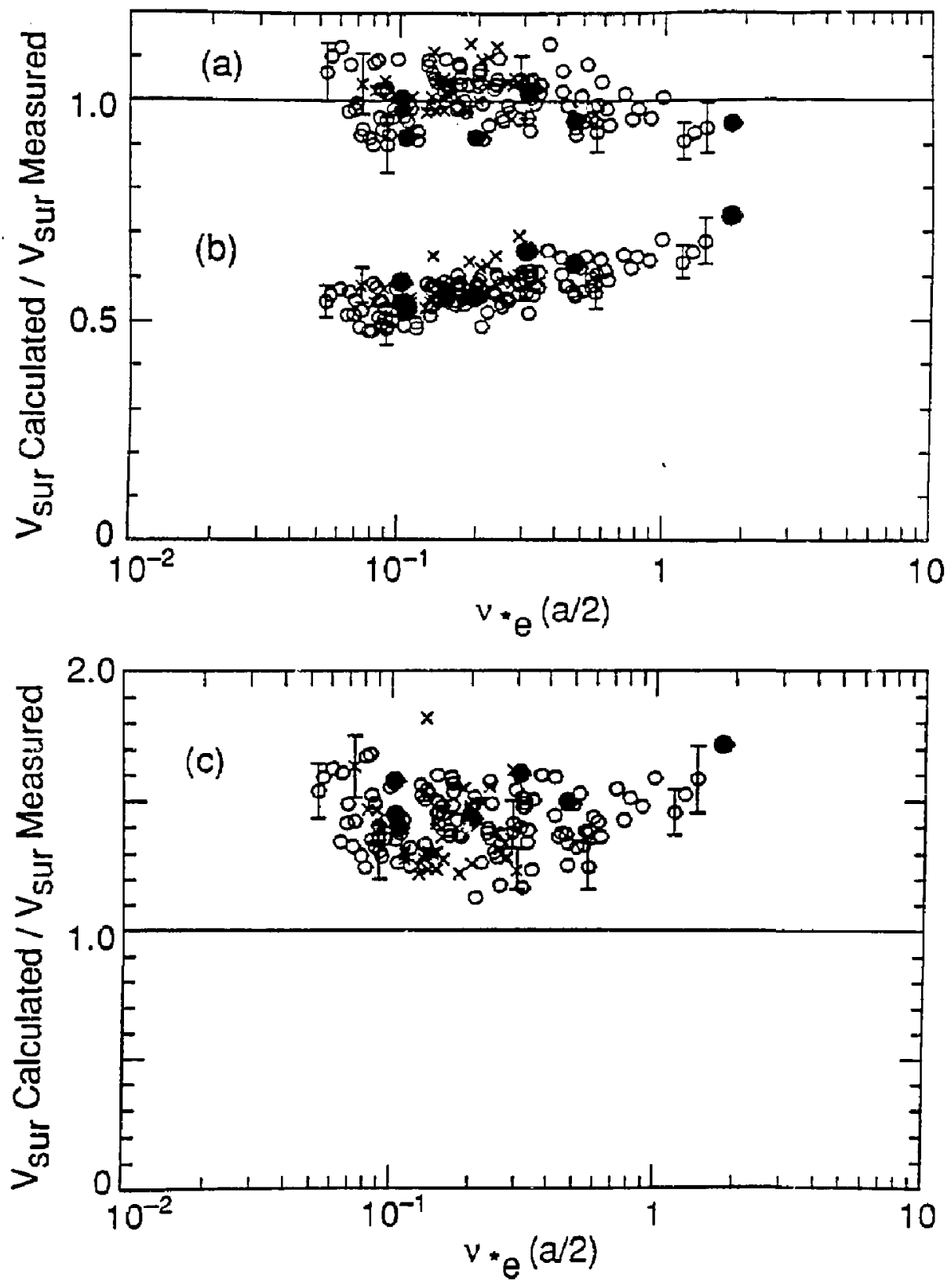

FIG. 8 


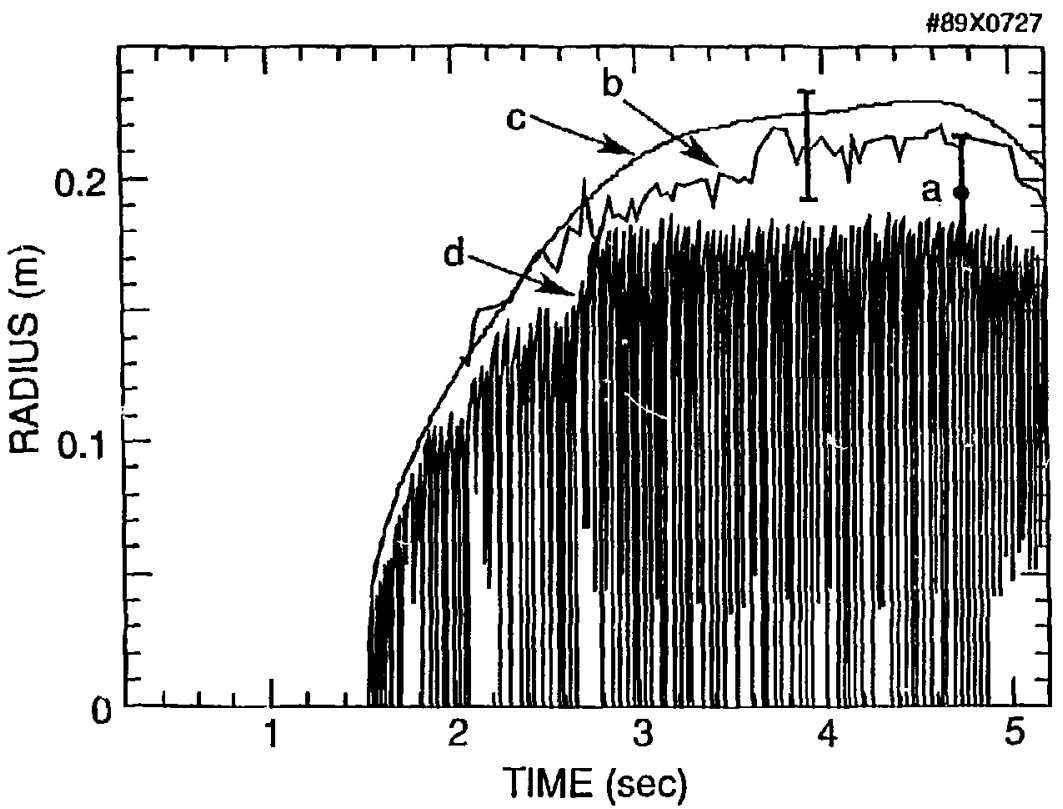

Fifr. 9 